\title{
Trends in sex differences in the receipt of quality of care indicators among adults with diabetes: United States 2002-2011
}

\author{
Joni S. Williams ${ }^{1,2,3}$, Kinfe G. Bishu ${ }^{4,5}$, Alessandra St. Germain ${ }^{4}$ and Leonard E. Egede ${ }^{1,2,3^{*}}$ (D)
}

\begin{abstract}
Background: Evidence suggests disparities in quality of care (QoC) indicators based on sex exist in adults diagnosed with diabetes; however, this research is limited. Therefore, the objective of this research study was to assess differences in QOC indicators in a nationally representative sample of men and women with diabetes.

Methods: Cross-sectional study of 17,702 men and women ( $\geq 18$ years of age) with diabetes from the 2002-2011 Medical Expenditure Panel Survey Household Component. Sex was the main predictor variable, and the dependent variables were five binary indicators to measure QOC, which included testing of hemoglobin A1c, examining feet annually, getting eyes dilated, checking blood pressure, and visiting the doctor annually. Sample demographics by sex were assessed. Unadjusted analyses were computed for descriptive statistics by sex and proportions of QOC indicators over time. Logistic regression evaluated associations between QOC indicators and sex, while controlling for sociodemographic characteristics, time, and comorbid conditions.
\end{abstract}

Results: Approximately $44 \%$ and $56 \%$ of the sample was comprised of men and women, respectively. Unadjusted analyses showed significant differences in A1c testing $(p<0.001)$ and foot examinations $(p=0.002)$ for the entire sample, and significant differences in A1c testing $(p=0.027)$, foot examinations $(p=0.01)$, and dilated eye exams $(p=0.026)$ among men and A1c testing $(p<0.001)$ among women overtime. Adjusted analyses found women to be significantly more likely to have dilated eye examinations during a given year ( $\mathrm{OR}=1.14 ; 95 \% \mathrm{Cl} 1.04,1.24)$, to get their blood pressure checked by a doctor in a given year $(\mathrm{OR}=1.44 ; 95 \% \mathrm{Cl} 1.13,1.84)$, and to visit a doctor annually $(\mathrm{OR}=1.39 ; 95 \% \mathrm{Cl} 1.22,1.58)$ compared to men.

Conclusions: In this sample of adults with diabetes, women had significantly higher odds of receiving quality of care compared to men. These findings suggest the importance of educating patients about appropriate metrics of diabetes management, especially men, and the need for continuous empowerment of women to receive proper and optimal care. Additional research is needed to identify causes and reduce sex and gender disparities associated with diabetes quality of care.

Keywords: Sex differences, Diabetes, Quality of care, Adults, Disparity

\footnotetext{
* Correspondence: legede@mcw.edu

'Department of Medicine, Medical College of Wisconsin, 9200 W. Wisconsin

Avenue, Clinical Cancer Center Building Suite C5400, Milwaukee WI 53226, USA

${ }^{2}$ Center for Patient Care and Outcomes Research (PCOR), Medical College of Wisconsin, Milwaukee WI 53226, USA

Full list of author information is available at the end of the article
} 


\section{Background}

More than 29 million people in the United States are living with diabetes; of which, one in four are unaware they have diabetes [1]. Diabetes results in significant morbidity and mortality associated with complications such as adult-onset blindness, kidney failure, heart disease, stroke, and loss of limbs [1]. In 2010, 60\% of nontraumatic lower-limb amputations occurred in patients with diabetes, and in 2011, diabetes was the number one cause of kidney failure [1]. In addition to its association with serious and adverse complications, diabetes also accounts for a tremendous financial burden to diagnosed patients and an economic burden to society. Evidence suggests women typically have higher healthcare costs for diabetes care compared to men [2], spending approximately $\$ 8,331$ annually compared to $\$ 7,458$ for men $[2,3]$. The average cost of diabetes care for the U.S. is $\$ 245$ billion, with $43 \%$ of that cost going towards hospital inpatient care [3]. Since 2007, the cost of diabetes care has risen $41 \%$, yet the disease remains the seventh leading cause of death in the U.S. [1, 2, 4].

Over 15 million men and 13 million women have diabetes [1]. Sex and gender are important characteristics to consider in diabetes care as predisposition and exposure to multiple genetic, biological, cultural, environmental, and psychosocial risk factors, among others, contribute to differences in outcomes between men and women $[5,6]$. For example, in women with diabetes, evidence suggests an increased risk for cardiovascular disease and mortality compared to women without diabetes and men, in part due to alterations in and lower levels of high-density lipoprotein cholesterol (HDL-C) and its associated lipid transfer proteins and enzymes, all of which protect against the development of atherosclerosis [5]. In addition, endocrine imbalances and psychosocial stress are associated with poorer outcomes in women with diabetes compared to men with diabetes [6]. Finally, lifestyle and behavioral factors contribute considerably to sex and gender differences in diabetes outcomes [6]. Recognizing, understanding, and being aware of differences between men and women with diabetes argues the relevance of considering sex and gender when managing diabetes and providing clinical care.

It is well known that quality care and optimal management in diabetes require a multifaceted and comprehensive approach. Quality of care (QoC) in patients with diabetes is of paramount importance and can be assessed using multiple performance indicators and process and quality measures such as testing the glycosylated hemoglobin A1c (HbA1c), checking the blood pressure (BP), examining the feet, receiving dilated eye examinations, and visiting the doctor. According to the American Diabetes Association (ADA), HbA1c testing should be performed at least 2-4 times a year depending on whether specific treatment goals are being met [4].
Additionally, to manage cardiovascular risk factors, the ADA recommends blood pressure be measured at each routine visit [4]. Similarly, a comprehensive foot evaluation and eye examinations are recommended to identify risk factors for ulcers and amputations and retinopathy, respectively [4]. These processes of care, along with others such as periodic testing of lipids and albumin, aspirin use, and smoking cessation, are needed to favorably affect health outcomes by achieving glycemic control, preventing the development of long-term complications, and reducing the financial burden associated with diabetes management [4, 7-10].

Compared with studies that assess differences in cardiovascular risk factors among adults with diabetes, less attention has been given to examining differences in receipt of QoC indicators within the same population [11-17]. Given observed differences between men and women with diabetes in risk factor control for cardiovascular disease, it is important to understand potential differences in how processes of care are received to understand the current climate of practice and establish new premises for research, policies, and clinical care. Therefore, in this study, we examined sex differences in receiving QoC indicators among a nationally representative sample of adults with diabetes. Based on evidence from the current literature, we hypothesized that women with diabetes would receive more QoC indicators compared to men with diabetes.

\section{Methods}

\section{Data source and study population}

The Medical Expenditure Panel Survey Household Component (MEPS-HC) data from 2002-2011 were used to examine the association between QoC and sex among adults with diabetes (aged $\geq 18$ years). In this retrospective study, we identified 17,702 (weighted sample of $17,857,174$ ) adults with self-reported diabetes from MEPS-HC. MEPS is a survey of a nationally representative U.S. civilian, noninstitutionalized population and is administered by the Agency for Healthcare Research and Quality [18-20]. The AHRQ validates MEPS as a self-reported instrument by administering many quality assurance procedures like validation of an interviewer's work and also comparing MEPS numbers with other data source numbers like the Census Bureau and National Health Interview Survey (NHIS). MEPS obtains information on participants' quality of care, as well as information on medical spending, demographics, and socioeconomics [20]. The MEPS sample is drawn from reporting units in the previous year's NHIS, a nationally representative sample with oversampling for non-Hispanic Blacks and Hispanics of the U.S. civilian, non-institutionalized population [18-20].

To ensure sufficient sample size and robust estimation for our analyses, we pooled 10 years of MEPS data. Because they have a common variance structure, we can 
ensure compatibility and comparatively of our variables within the complex sample design. Our study accounts for the sampling weights, clustering, and stratification design to estimate the nationally representative study for the U.S. population [20].

\section{Measures \\ Variables of interest}

All measures are based on previously validated questionnaires that are publicly available on the MEPS website [18-20]. The dependent variables in this study were five binary indicators to measure the $\mathrm{QoC}$ for patients with diabetes, which reported receipt of the following during the past year: 1) having at least two HbA1c tests, 2) having at least one foot examination, 3) having a dilated eye examination, 4) having blood pressure checked by a doctor, and 5) having at least one visit to the doctor's office for care. The primary independent variable was sex, which was dichotomized as female versus male.

\section{Controlled covariates}

All controlled covariates used for analysis were based on self-report. Binary indicators of comorbidities were based on a positive response to a question, "Have you ever been diagnosed with...?" Cardiovascular disease (CVD) indicates a positive response to coronary heart disease, angina, myocardial infarction, or other heart diseases. Race/Ethnic groups were categorized into: Non-Hispanic White (NHW), Non-Hispanic Black (NHB), Hispanic, or others. Education was categorized into: less than high school ( $\leq$ grade 11), high school (grade 12), and college or more (grade $\geq 13$ ). Marital status was categorized into: married, non-married, and never married. Age was categorized into: 18-44, 45-64, and $\geq 65$ years. Metropolitan Statistical Area (MSA) was coded by MSA status $(\mathrm{MSA}=1$, Non-MSA $=0)$. Census region was categorized into: Northeast, Midwest, South, and West. Health insurance was categorized into: private, public only, and uninsured throughout the year. The income level was defined as a percentage of the poverty level and grouped into four categories: poor $(<125 \%)$, low income ( $125 \%$ to less than $200 \%)$, middle income (200\% to less than $400 \%$ ), and high income $(\geq 400 \%)$. Calendar year was grouped into three consecutive years of 2002/05, 2006/09, 2010/11 for the pooled data.

\section{Analysis}

The baseline characteristics of adults with diabetes are presented by sex, with percentage differences for categorical variables tested using $\chi^{2}$ tests. Bivariate analyses were used to compare the trends of receiving QoC and then trends by sex. We also used multiple logistic regression to examine factors associated with sex and receiving QoC variables. Models controlled for age, race/ethnicity, marital status, education, insurance status, MSA, census region, household income, comorbidities, and time trend. For interpretation, we use the odds ratio coefficient of the logistic regressions.

F-adjusted mean residual goodness-of-fit was applied to test the adequacy of the models. After fitting the logistic regression models, taking the survey design into account, the F-adjusted mean residual goodness-of-fit suggested no evidence of lack of fit [21]. We used the link test that considers complex survey design as a diagnostic test to examine the model specification error. We verified the evidence of proper specification of the model $[22,23]$. Using the Variance Inflation Factor (VIF) test, it was determined that no multicollinearity problems existed between predictors of the model. We performed all analyses at the person-level using Stata 14 [24]. Estimates that are statistically significant at the $p<0.05$ level are discussed in the paper.

\section{Results}

Characteristics of U.S. adults with diabetes population

Characteristics of adults with diabetes in this study are summarized in Table 1. The unweighted sample size was 17,702 for adults with diabetes (aged $\geq 18$ years) and represented a weighted sample of $17,857,174$ within the U.S. population. Of the unweighted sample, $56.4 \%$ were women and more likely to be in age group 18-44 years and elderly ( $\geq 65$ years), be minority, single, have a lower education level, be publicly insured, have poor and low income, and have a comorbid condition of cardiovascular disease, asthma, joint pain and arthritis.

\section{Quality of care changes over time}

Among adults with diabetes, receiving an $\mathrm{HbA1c}$ test at least twice during the year and receiving at least one foot examination during the year were significantly associated with time trend (Table 2). Receiving an HbA1c test at least twice during the year rose consistently from $78.1 \%$ in $2002 / 05$ to $83.5 \%$ in $2010 / 11$. Receiving at least one foot examination during the year decreased from $71.2 \%$ in $2002 / 05$ to $67.2 \%$ in $2006 / 09$ and then rose to $69.6 \%$ in $2010 / 11$.

Quality of care indicators by sex overtime among adults with diabetes is shown in Table 3. Receiving an HbA1c test at least twice during the year was significantly associated with time trend, and it consistently increased overtime for both men and women. Having a dilated eye exam and having at least one foot examination during the year were significantly associated with time trend for men only. Having at least one foot examination in men decreased from $72.3 \%$ in $2002 / 05$ to $67.9 \%$ in $2006 / 09$ and then increased to $71.3 \%$ in $2010 / 11$. Having a dilated eye exam in men consistently increased from $61.0 \%$ in $2002 / 05$ to $65.9 \%$ in $2010 / 11$. 
Table 1 Sample demographics by sex among adults with diabetes

\begin{tabular}{|c|c|c|c|c|}
\hline & All $(n=17,702)$ & Men $(n=7715)$ & Women $(n=9987)$ & $P$-value \\
\hline Age & & & & $<0.001^{* * *}$ \\
\hline $18-44$ years & 13.2 & 12.2 & 14.1 & \\
\hline $45-64$ years & 46.9 & 49.6 & 44.4 & \\
\hline $65+$ years & 39.9 & 38.2 & 41.5 & \\
\hline Race/Ethnicity & & & & $<0.001^{* * *}$ \\
\hline Non-Hispanic White & 64.6 & 68.4 & 61.0 & \\
\hline Non-Hispanic Black & 15.3 & 12.3 & 18.0 & \\
\hline Hispanic & 13.5 & 12.7 & 14.3 & \\
\hline Non-Hispanic Other & 6.6 & 6.6 & 6.7 & \\
\hline Marital Status & & & & $<0.001^{* * *}$ \\
\hline Married & 58.5 & 70.1 & 47.4 & \\
\hline Unmarried & 32.5 & 21.7 & 42.8 & \\
\hline Never married & 9.1 & 8.3 & 9.8 & \\
\hline Educational Level & & & & $<0.001^{* * *}$ \\
\hline$<$ High School Graduate & 26.9 & 24.1 & 28.2 & \\
\hline High School Graduate & 34.5 & 32.1 & 36.9 & \\
\hline College Graduate & 39.3 & 43.9 & 35.0 & \\
\hline Insurance Status & & & & $<0.001^{* * *}$ \\
\hline Private Insurance & 61.0 & 66.2 & 55.97 & \\
\hline Public insurance & 31.5 & 26.1 & 36.6 & \\
\hline No Insurance & 7.6 & 7.7 & 7.4 & \\
\hline Annual Family Income Level & & & & $<0.001^{* * *}$ \\
\hline Poor/Negative/Near Poor Income & 19.9 & 15.1 & 24.6 & \\
\hline Low Income & 16.2 & 14.1 & 18.3 & \\
\hline Middle Income & 30.8 & 31.2 & 30.3 & \\
\hline High Income & 33.1 & 39.6 & 26.8 & \\
\hline Metropolitan Statistical Area & & & & .101 \\
\hline Metropolitan Statistical Area & 79.7 & 79.0 & 80.5 & \\
\hline Non-Metropolitan Statistical Area & 20.3 & 21.0 & 19.6 & \\
\hline Region & & & & 0.556 \\
\hline Northeast & 17.2 & 17.3 & 18.1 & \\
\hline Midwest & 21.1 & 21.2 & 21.1 & \\
\hline South & 40.3 & 40.1 & 40.5 & \\
\hline West & 20.8 & 21.4 & 20.2 & \\
\hline Hypertension & & & & 0.126 \\
\hline No & 26.8 & 27.7 & 26.0 & \\
\hline Yes & 73.2 & 72.3 & 74.0 & \\
\hline Cardiovascular Disease & & & & $0.001^{* *}$ \\
\hline No & 68.1 & 66.3 & 69.8 & \\
\hline Yes & 31.9 & 33.7 & 30.2 & \\
\hline Stroke & & & & 0.819 \\
\hline No & 89.9 & 90.0 & 89.8 & \\
\hline Yes & 10.1 & 10.0 & 10.2 & \\
\hline
\end{tabular}


Table 1 Sample demographics by sex among adults with diabetes (Continued)

\begin{tabular}{|c|c|c|c|c|}
\hline Emphysema & & & & 0.266 \\
\hline No & 95.1 & 94.8 & 95.4 & \\
\hline Yes & 4.9 & 5.2 & 4.7 & \\
\hline Asthma & & & & $<0.001^{* * *}$ \\
\hline No & 86.3 & 90.6 & 82.2 & \\
\hline Yes & 13.7 & 9.4 & 17.8 & \\
\hline Joint Pain & & & & $<0.001^{* * *}$ \\
\hline No & 43.8 & 49.0 & 38.8 & \\
\hline Yes & 56.2 & 51.0 & 61.2 & \\
\hline Arthritis & & & & $<0.001^{* * *}$ \\
\hline No & 51.2 & 59.8 & 42.9 & \\
\hline Yes & 48.8 & 40.2 & 57.1 & \\
\hline Year Categories & & & & 0.511 \\
\hline 2002-2005 & 33.9 & 33.3 & 34.4 & \\
\hline 2006-2009 & 42.6 & 42.8 & 42.4 & \\
\hline 2010-2011 & 23.5 & 23.9 & 23.0 & \\
\hline
\end{tabular}

$n=$ unweighted sample size. All numbers represent percentages

Statistically significant at ${ }^{*} p<0.05,{ }^{* *} p<0.01$, and ${ }^{* * *} p<0.001$

\section{Receipt of quality of care}

In the fully adjusted multiple logistic regression model (Table 4), women had statistically significant higher odds of receiving a dilated eye exam compared to men $(\mathrm{OR}=1.14$; 95\% CI 1.04-1.24). Women had statistically significant higher odds of getting their blood pressure checked by a doctor during the year $(\mathrm{OR}=1.44 ; 95 \% \mathrm{CI}$ 1.13-1.84) in comparison to men. Compared to men, women had significantly higher odds of making at least one visit to the doctor for care $(\mathrm{OR}=1.39$; 95\% CI 1.22-1.58). Sex was not significantly associated with higher or lower odds of having HbA1c tested at least twice or having at least one foot examination during the year.

\section{Discussion}

In this sample of adults with diabetes, women had significantly higher odds of receiving certain QoC indicators compared to men after adjusting for confounding factors. Specifically, women were significantly more likely to visit a doctor, and receive blood pressure checks and eye examinations in comparison to men with diabetes. These findings suggest that, compared to men with diabetes in this national sample, women were more likely to receive QoC processes of care. Given the cross-sectional design of this study, definitive causes for this difference between men and women cannot be identified; however, it is possible that women had higher odds of receiving QoC because of their increased rate of utilization, desire for preventive healthcare services, higher prevalence of comorbid conditions, and longer life expectancies [16, 25-28].

Our findings are supported by evidence from previous studies evaluating differences in QoC indicators between men and women with diabetes. In this sample of adults, we found women to have higher odds of visiting a doctor annually and receiving QoC indicators such as blood pressure measurements and dilated eye examinations. This is similar to the findings of Chou et al and Tseng et al, who also found women more likely to receive certain performance indicators such as eye examinations [12, 15]. Similarly, among adults enrolled in managed care plans, a sex disparity was observed where women with diabetes, again, had a higher relative risk for receiving eye

Table 2 Unadjusted proportions for quality of care indicators overtime among adults with diabetes

\begin{tabular}{|c|c|c|c|c|}
\hline Quality of care indicators & $2002-2005$ & 2006-2009 & 2010-2011 & $P$-value \\
\hline HbA1c test $2+$ times during year? & 78.1 & 80.0 & 83.5 & $<0.001^{* * *}$ \\
\hline Feet checked during year? & 71.2 & 67.2 & 69.6 & $0.002^{* *}$ \\
\hline Dilated eye exam during year? & 61.9 & 62.5 & 62.9 & 0.063 \\
\hline Blood pressure checked by doctor during year? & 97.8 & 97.9 & 98.1 & 0.648 \\
\hline Visited doctor during last 12 months? & 91.2 & 91.0 & 90.3 & 0.455 \\
\hline
\end{tabular}

All numbers represent percentages. Statistically significant at ${ }^{*} p<0.05,{ }^{* *} p<0.01$, and ${ }^{* * *} p<0.001$ 
Table 3 Descriptive statistics for quality of care indicators by sex overtime among adults with diabetes

\begin{tabular}{|c|c|c|c|c|c|c|c|c|}
\hline \multirow[t]{2}{*}{ Quality of care indicators } & \multicolumn{4}{|l|}{ Men } & \multicolumn{4}{|l|}{ Women } \\
\hline & $2002-2005$ & 2006-2009 & $2010-2011$ & $P$-value & $2002-2005$ & $2006-2009$ & 2010-2011 & $P$-value \\
\hline $\mathrm{HbA} 1 \mathrm{c}$ test $2+$ times during year? & 77.9 & 80.4 & 82.6 & $0.027^{*}$ & 78.3 & 79.6 & 84.3 & $<0.001^{* * *}$ \\
\hline Feet checked during year? & 72.3 & 67.9 & 71.3 & $0.010^{*}$ & 70.1 & 66.8 & 68.0 & 0.089 \\
\hline Dilated eye exam during year? & 61.0 & 61.5 & 65.9 & $0.026^{*}$ & 62.6 & 63.5 & 64.3 & 0.631 \\
\hline Blood pressure checked by doctor during year? & 97.2 & 97.9 & 97.7 & 0.323 & 98.3 & 97.9 & 98.5 & 0.177 \\
\hline Visited doctor during last 12 months? & 90.1 & 90.2 & 88.7 & 0.326 & 92.1 & 91.8 & 91.9 & 0.904 \\
\hline
\end{tabular}

All numbers represent percentages. Statistically significant at ${ }^{*} p<0.05,{ }^{* *} p<0.01$, and ${ }^{* * *} p<0.001$

examinations compared to men [17]. Additionally, in our study, we did not find sex differences in HbA1c testing for QoC indicators. This is similar to the findings of $\mathrm{Yu}$ et al [14] and Tseng et al [15], who found no sex differences in HbA1c testing among adults with diabetes. In contrast to our findings, there is evidence to support poorer QoC in women with diabetes compared to men, despite QoC being a priority for most women [11, 13, 14, 17, 29]. For example, in a cross-sectional study to assess gender differences across racial and ethnic groups in QoC for diabetes, Correa-de-Araujo and colleagues found NHW women less likely to receive retinal eye and foot examinations than NHW men [11]. Evidence suggests several reasons women possibly have higher risks of not reaching targeted recommendations compared to men; these include 1) lower income and education in women, 2) opposing lifestyles, attitudes, and beliefs, 3) missed clinical goals, particularly for BP, and low-density lipoprotein-cholesterol (LDL-C) and even for composite control of BP, HDL-C, LDL-C, and HbA1c, 4) differences in rates of modifiable risk factors, and 5) lower screening rates for women compared to men [11, 13, 14, 17, 29, 30]. Lastly, some studies have found no differences in QoC indicators between men and women; however, recommendations were noted that improvements in QoC are needed overall for all adults [11, $12,14,29,31]$.

The findings of our study are important because they reemphasize the importance of improved $\mathrm{QoC}$ for both men and women with diabetes. In the nation's health agenda to reduce disparities and improve the health of all Americans, Healthy People 2020 shared recommendations for certain QoC that must be received by patients with diabetes [32]. Despite prior evidence from the remote and recent past showing progress in QoC trends for patients with diabetes [32-34], many adults are still not reaching recommended goals for diabetes QoC. For example, except for $\mathrm{HbA1c}$ testing at least twice a year and annual dilated eye examinations, adults with diabetes ( $\geq 18$ years of age) did not meet other Healthy People 2020 recommendations for preventive care practices [32]. This trend has also been acknowledged in the literature [35-36]. A study conducted in patients with diabetes found that only $14 \%$ of physicians document proper foot examinations on their patients [35]. To complicate this issue, it is often reported that primary care physicians do not have the time or training to properly educate patients with diabetes on appropriate self-care of their feet [36]. In addition to difficulties meeting preventative care goals, it has been reported that, between 2009 and 2012, $71 \%$ of adult patients with diabetes did not meet recommended goals for blood pressure [4].

While this study adds to the current literature assessing disparities in QoC between men and women with diabetes, there are limitations that must be reported. First, cross-sectional studies are limited in being able to draw causal associations. Second, consistent quality indicators and approaches for measuring QoC in diabetes are lacking in the current literature, where the focus was often on intermediate outcomes such as goal attainment (i.e., HbA1c < 7\%, systolic and diastolic $\mathrm{BP}<140 / 90 \mathrm{mmHg}$, $\mathrm{LDL}-\mathrm{C}<100 \mathrm{mg} / \mathrm{dL}$, urine microalbumin, etc.) in different combinations, and not solely on receipt of services. Because of these varied approaches, it was difficult to obtain a comprehensive assessment of QoC for adults with diabetes. In addition, performance on other quality,

Table 4 Adjusted logistic regression for quality of care indicators among adults with diabetes

\begin{tabular}{llll}
\hline Quality of care indicators & Odds ratio & $95 \%$ Confidence interval & $P$-value \\
\hline HbA1c test 2+ times during year? & 1.01 & $(0.89,1.14)$ & 0.848 \\
Feet checked during year? & 0.91 & $(0.83,1.00)$ & 0.066 \\
Dilated eye exam during year? & 1.14 & $(1.04,1.24)$ & $0.003^{* *}$ \\
Blood pressure checked by doctor during year? & 1.44 & $(1.13,1.84)$ & $0.004^{* *}$ \\
Visited doctor during last 12 months? & 1.39 & $(1.22,1.58)$ & $<0.001^{* * *}$ \\
\hline
\end{tabular}

Statistically significant at ${ }^{*} p<0.05,{ }^{* *} p<0.01$, and ${ }^{* * *} p<0.001$. Reference Group: men

Adjusted for: age, race/ethnicity, sex, marital status, education, insurance, income, metropolitan statistical area, region, income, comorbid conditions (hypertension, cardiovascular disease, stroke, emphysema, asthma, joint pain, and arthritis) and time 
process, and intermediate indicators such as LDL-C, smoking, obesity, albumin-creatinine ratio, and estimated glomerular filtration rate (eGRF) were not included in these analyses. Third, when adjusting for sociodemographic characteristics, comorbid conditions, and time trend in the analyses, adjustments were not made for potential confounding variables such as racism and perceived discrimination, patient-provider communication and attitudes, and dissatisfaction with care, all of which may have influenced patient utilization and patient-provider decision-making. Fourth, given the design of MEPS data, it is not possible to distinguish between type 1 and type 2 diabetes, limiting analyses on sex-related differences in the QOC indicators by type of diabetes diagnosis. Therefore, the findings reported herein indicate differences by sex for all individuals with diabetes, regardless of type.

\section{Conclusions}

The results of our study are important and provide additional information about sex differences in specific QoC indicators among adults with diabetes. In this nationally representative sample of men and women with diabetes, women had higher odds of visiting a doctor, and receiving BP checks and eye examinations compared to men after adjusting for relevant confounding factors. Despite women performing better for specific QoC indicators, more progress is needed for both men and women to meet recommended targets.

Overall, these results indicate a need for improved QoC in adults with diabetes, as well as a need for uniformity in constructs and quality indicators and assessments to measure $\mathrm{QoC}$ in diabetes care. Additional research is needed to assess differences in QoC and to identify facilitators and barriers to appropriate $\mathrm{QoC}$ between men and women with diabetes. Policies are needed that propose strategies for addressing disparate care between men and women with diabetes. Suitable sex-specific guidelines are warranted in clinical practice for minimizing suboptimal QoC in adults with diabetes and increasing the number of adults who meet QoC targets and recommendations. Finally, it is important that providers discuss QoC processes with their patients to educate and inform them about appropriate diabetes management, empowering them to participate in the decision-making processes to ensure QoC indicators are received and targeted goals met.

\footnotetext{
Abbreviations

ADA: American diabetes association; AHRQ: Agency for healthcare research and quality; BP: Blood pressure; CVD: Cardiovascular disease; HbA1c: glycosylated hemoglobin A1c; HDL-C: High-density lipoprotein-cholesterol; LDL-C: Low-density lipoprotein-cholesterol; MEPS: Medical expenditure panel survey; MEPSHC: Medical expenditure panel survey household component; mg/dL: milligrams per deciliter; mmHg: millimeters of mercury; MSA: Metropolitan statistical area; NHB: Non-hispanic black; NHIS: National health interview survey; NHW: Nonhispanic white; QoC: Quality of care; U.S.: United States
}

\section{Acknowledgements}

Not applicable.

\section{Funding}

This study was supported by the National Institute of Diabetes and Digestive and Kidney Diseases (grant K24DK093699, Principal Investigator: Leonard Egede, MD, MS)

\section{Availability of data and materials}

The datasets generated and analyzed during the current study are available in the Agency for Healthcare Research and Quality (AHRQc). Medical Expenditure Panel Survey. Available from http://meps.ahrq.gov/mepsweb/ data_stats/download_data_files.jsp.

\section{Authors' contributions}

LEE obtained funding for the study. LEE and KGB acquired the data. JSW and LEE designed the study. JSW, KGB, AS, and LEE analyzed and interpreted the data, drafted the article, and critically revised the manuscript for important intellectual content. All authors approved the final manuscript.

\section{Competing interests}

The authors declare that they have no competing interests.

Consent for publication

Approval to publish is provided for publicly available MEPS data.

\section{Ethics approval and consent to participate}

This analysis used secondary data from the Medical Expenditures Panel Survey, as such all ethics approvals and consent to participate were waived.

\section{Publisher's Note}

Springer Nature remains neutral with regard to jurisdictional claims in published maps and institutional affiliations.

\section{Author details}

${ }^{1}$ Department of Medicine, Medical College of Wisconsin, 9200 W. Wisconsin Avenue, Clinical Cancer Center Building Suite C5400, Milwaukee WI 53226, USA. ${ }^{2}$ Center for Patient Care and Outcomes Research (PCOR), Medical College of Wisconsin, Milwaukee WI 53226, USA. ${ }^{3}$ Division of General Internal Medicine, Center for Patient Care and Outcomes Research, Medical College ofWisconsin, 9200 W. Wisconsin Ave, Milwaukee WI 53226, USA. ${ }^{4}$ Center for Health Disparities Research, Department of Medicine, Medical University of South Carolina, 135Rutledge Avenue, Room 280, MSC 250593, Charleston SC 29425 , USA. ${ }^{5}$ Department of Medicine, Division of General Internal Medicine and Geriatrics, Medical University of South Carolina, 171 Ashley Avenue,

Charleston SC 29425, USA.

Received: 27 October 2016 Accepted: 31 May 2017

Published online: 06 June 2017

\section{References}

1. Centers for Disease Control and Prevention. National diabetes statistics report: estimates of diabetes and its burden in the United States, 2014. Atlanta, GA: US Department of Health and Human Services; 2014.

2. Zhuo $X$, Zhang $P$, Hoerger J. Lifetime direct medical costs of treating type 2 diabetes and diabetic complications. Am J Prev Med. 2013;45(3):253-61.

3. American Diabetes Association. The Cost of Diabetes. 2013. Available from http://www.diabetes.org/advocacy/news-events/cost-of-diabetes.html. Web accessed 13 June 2016.

4. American Diabetes Association. Standards of Medical Care in Diabetes 2016. Published 2016.http://care.diabetesjournals.org/content/suppl/2015/12/21/39. Supplement_1.DC2/2016-Standards-of-Care.pdf. Web accessed 26 July 2016.

5. Russo GT, Horvath KV, Di Benedetto A, Giandalia A, Cucinotta D, Asztalos B. Influence of menopause and cholesteryl ester transfer protein (CETP) TaqlB polymorphism on lipid profile and HDL subpopulations distribution in women with and without type 2 diabetes. Atherosclerosis. 2010;210(1): 294-301.

6. Kautzky-Willer A, Harreiter J, Pacini G. Sex and gender differences in risk, pathophysiology and complications of type 2 diabetes mellitus. Endocr Rev. 2016;37(3):278-316. 
7. American Diabetes Association. Strategies for improving care. Sec. 1. In Standards of Medical Care in Diabetesd2016. Diabetes Care. 2016;39 Suppl 1:S6-S12.

8. Bayer FJ, Galusha D, Slade M, Chu IM, Taiwo O, Cullen MR, et al. Process of care compliance is associated with fewer diabetes complications. Am J Manag Care. 2014;20(1):41-52.

9. Sidorov J, Shull R, Tomcavage J, Girolami S, Lawton N, Harris R. Does diabetes disease management save money and improve outcomes? a report of simultaneous short-term savings and quality improvement associated with a health maintenance organization-sponsored disease management program among patients fulfilling health employer data and information set criteria. Diabetes Care. 2002;25(4):684-9.

10. Harman JS, Scholle SH, Ng JH, Pawlson LG, Mardon RE, Haffer SC, et al. Association of health plans' healthcare effectiveness data and information set (HEDIS) performance with outcomes of enrollees with diabetes. Med Care. 2010;48(3):217-23.

11. Correa-de-Araujo R, McDermott K, Moy E. Gender differences across racial and ethnic groups in the quality of care for diabetes. Women's Health Issues. 2006;16(2):56-65.

12. Chou AF, Brown AF, Jensenc RE, Shih S, Pawlson G, Scholle SH. Gender and racial disparities in the management of diabetes mellitus among Medicare patients. Women's Health Issues. 2007;17(3):150-61.

13. Rossi MC, Cristofaro MR, Gentile S, Lucisano G, Manicardi V, Mulas MF, et al. Sex disparities in the quality of diabetes care: biological and cultural factors may play a different role for different outcomes. Diabetes Care. 2013;36: 3162-8.

14. Yu MK, Lyles CR, Bent-Shaw LA, Young BA. Sex disparities in diabetes processes of care measures and self-care in high-risk patients. J Diab Res. 2013;2013:575814

15. Tseng C, Sambamoorthi U, Rajan M, Tiwari A, Frayne S, Findley P, et al. Are there gender differences in diabetes care among elderly Medicare enrolled Veterans? J Gen Int Med. 2006;21:S47-53.

16. Correa-de-Araujo R, Clancy CM. Catalyzing quality of care improvements for women. Women's Health Issues. 2006;16:41-3.

17. Bird CE, Fremont AM, Bierman AS, Wickstrom S, Shah M, Rector T, et al. Does quality of care for cardiovascular disease and diabetes differ by gender for enrollees in managed care plans? Women's Health Issues. 2007; 17:131-8

18. Agency for Healthcare Research and Quality (AHRQa). Methodology Report \# 27, Sample design of the 2011 Medical Expenditure Panel Survey Insurance Component 2013a, Available from http://meps.ahrq.gov/data_ files/publications/mr27/mr27.pdf. Accessed 22 Aug 2014.

19. Agency for Healthcare Research and Quality (AHRQb). Medical Expenditure Panel Survey, 2011 Medical conditions 2013b, Available from http://meps. ahrq.gov/mepsweb/data_stats/download_data/pufs/h146/h146doc.pdf Accessed 20 Aug 2014

20. Agency for Healthcare Research and Quality (AHRQc). Medical Expenditure Panel Survey. 2011 Full year consolidated data file 2013c, Available from http://meps.ahrq.gov/mepsweb/data_stats/download_data_files.jsp. Accessed 18 Aug 2014

21. Archer KJ, Lemeshow S. Goodness-of-fit test for a logistic regression mode fitted using survey sample data. Stata J. 2006;6(1):97-105.

22. Musman S, Passos VMA, Silva IBR, Barreto SM. Evaluation of a prediction model for sleep apnea in patients submitted to polysomnography. J Bras Pneumol. 2011;37(1):75-84.

23. Cameroon AC, Trivedi PK. Microeconometrics using stata. College Station, Texas: StataCorp LP; 2010.

24. StataCorp. Stata Statistical Software: Release 14. College Station, TX: StataCorp, LP; 2015.

25. Bertakis KD, Azari R, Helms LJ, Callahan EJ, Robbins JA. Gender differences in the utilization of health care services. J Fam Pract. 2000;49(2):147-52.

26. Bertakis KD, Azari R. Patient gender differences in the prediction of medical expenditures. J Women's Health (Larchmt). 2010;19(10):1925-32.

27. Cohen SB, Ezzati-Rice T, Yu W. The utility of extended longitudinal profiles predicting future health care expenditures. Med Care. 2006;44(5 Suppl):145-53.

28. Leslie LA, Swider SM. Changing factors and changing needs of women's health care. Nurs Clin North Am. 1986;21(1):111-23.

29. Kosiak B, Sangl J, Correa-de-Araujo R. Quality of health care for older women: what do we know? Women's Health Issues. 2006;16:89-99.
30. Strom Williams JL, Lynch CP, Winchester R, Thomas L, Keith B, Egede LE. Gender differences in composite control of cardiovascular risk factors among patients with type 2 diabetes. Diabetes Technol Ther. 2014;16(7): $421-7$.

31. Owens GM. Gender differences in health care expenditures, resource utilization, and quality of care. J Manag Care Pharm. 2008;14(Suppl S):S2-6.

32. Centers for Disease Control and Prevention. Diabetes report card 2014. Atlanta, GA: Centers for Disease Control and Prevention, US Dept of Health and Human Services; 2015

33. Saaddine JB, Cadwell B, Gregg EW, Engelgau MM, Vinicor F, Imperatore G, et al. Improvements in diabetes processes of care and intermediate outcomes: United States, 1988-2002. Ann Intern Med. 2006;144:465-74.

34. Ali MK, Bullard KM, Saaddine JB, Cowie CC, Imperatore G, Gregg EW Achievement of goals in U.S. diabetes care, 1999-2010. N Engl J Med. 2013; 368:1613-24.

35. O'Brien KE, Chandramohan V, Nelson DA, Fischer JR, Stevens G, Poremba JA. Effect of a physician-directed educational campaign on performance of proper diabetic foot exams in an outpatient setting. J Gen Intern Med. 2003;18(4):258-65.

36. Barshes NR, Sigireddi M, Wrobel JS, Mahankali A., Robbins JM, Kougias P et al. The system of care for the diabetic foot: objectives, outcomes, and opportunities. Diabetic Foot Ankle. 2013;4. 10.3402/dfa.v4i0.21847.

\section{Submit your next manuscript to BioMed Central and we will help you at every step:}

- We accept pre-submission inquiries

- Our selector tool helps you to find the most relevant journal

- We provide round the clock customer support

- Convenient online submission

- Thorough peer review

- Inclusion in PubMed and all major indexing services

- Maximum visibility for your research

Submit your manuscript at www.biomedcentral.com/submit 